\title{
Round-up on design behaviour
}

\author{
After a year of intense activities, the University of Virginia-Nature Sustainability Expert Panel on behavioural science \\ for design is ready to share its main findings and eager to bring more experts on board.
}

E arly in 2019 , an exceptionally diverse group of scholars and practitioners (https://go.nature.com/2KXOXFR) met in New York to embark on an exciting journey - finding ways to integrate the knowledge and practice of design and behavioural experts in order to accelerate the societal transformations needed for global sustainability. Over the course of two days, more than 40 experts from across the world discussed and exchanged ideas and insights with passion and energy in order to set up a plan of work for the year ahead, under the auspices of Nature Sustainability.

Why behaviour and design? Behavioural sciences have offered invaluable insights into the drivers and motivations of enduse behaviour, as Klotz et al. explain in their Comment introducing the work of the expert panel. We certainly need that knowledge to incentivize individuals to act wisely when interacting with the natural environment. Wearing more layers to keep the thermostat down at home or in the office, and so reduce energy consumption, is an example of end-use pro-environmental behaviour. Any intervention to induce such behaviour is going to have impact for sustainability. Therefore, knowledge to enhance effectiveness of such interventions is very much in need. But the human-nature interface can be shaped more sustainably in the first place. In other words, the way we organize our lives, the systems we 'design' to carry out our activities, can be conceived with sustainability in mind. How? By activating sustainable design behaviour, as Klotz and colleagues explain. The core issue is to understand the mind set of designers, and the context in which they operate, to find ways to enable sustainable design decisions, for example designing buildings to be heated by renewable energy. And design for the built environment is not the only relevant context to which design behaviour applies; think, for example, of policy design. Strengthening the dialogue and cross-collaborations among design and behavioural experts is, therefore, the way forward to make progress on sustainability, and that is the main rationale behind this international expert panel.

Working together for almost a year, panel experts have focused on identifying the kind of knowledge needed in design for sustainability, ways in which design behaviour can contribute to sustainability science, how to measure the impact of behavioural interventions on design outcome and, finally, how to build capacity to carry out the kind of collaborations needed for work on design behaviour for sustainability. All their insights and recommendations are synthesized in a report ${ }^{1}$ that we are now excited to announce and share with our readers.

The experts have identified 20 highpriority questions. Among the key areas of focus, the experts emphasize designers' mental models as they relate to sustainability, design processes, how to conceptualize sustainability in design, endusers' perceptions of the designed object, misperceptions of sacrifice and risk related to pro-environmental behaviour and how to evaluate low-frequency behavioural interventions. One of the key messages the panellists emphasize is that, in order to pursue all those questions, there is need of different but well-integrated expertise as well as different methods and approaches. With the report now finalized, experts aim to move the initiative to the next stage, which entails bringing together an even wider pool of scholars, practitioners and, hopefully, policy makers to answer the 20 questions in view of finding actual sustainable solutions. Nature Sustainability hopes that the report will appeal to as many as possible among our readers and beyond, to stimulate more engagement with the panel experts, and ensure that the synthesized knowledge and recommendations they have put together will not sit on a shelf.

This is the second expert panel that Nature Sustainability has convened since we launched in 2018. Our plan going forward is to continue to endorse one such initiative every year as a way to foster direct dialogue with our readers and the broad community, with the aim of stimulating thinking and action where we feel is most urgently needed. Although fully assessing the impact of these convening efforts - and any other activity they generate afterwards - remains challenging, the feedback we have received so far from those involved is

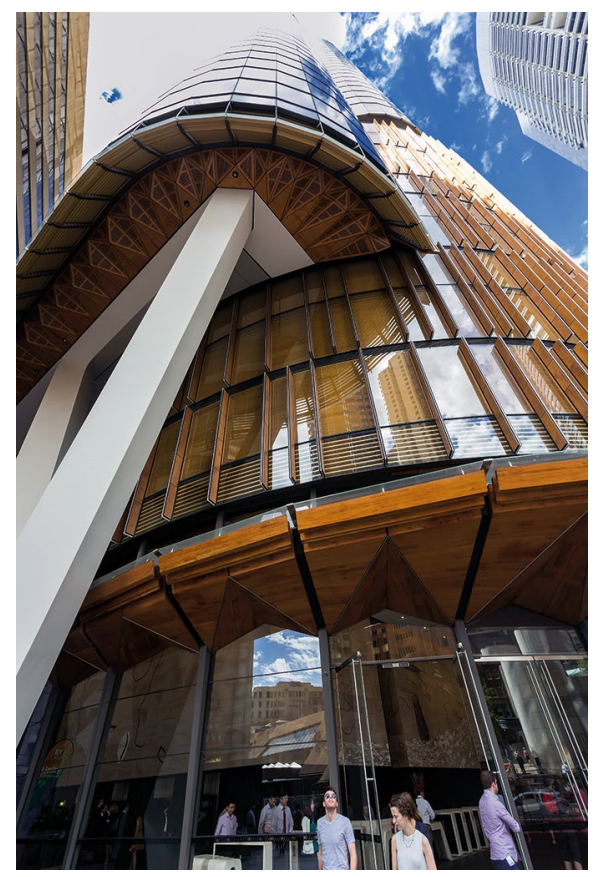

Credit: Paul Lovelace / Alamy Stock Photo

incredibly encouraging. We strongly believe in the value of bringing experts together to enable new collaborations and ideas. Breaking silos and enabling dialogue is essential to allow for actionable sustainable solutions, and Nature Sustainability will continue to promote the value of practicing cross-disciplinary efforts. We are sure that our readers are on board with us on this stimulating and fulfilling journey.

\section{"Breaking silos and enabling dialogue is essential to allow for actionable sustainable solutions"}

Published online: 10 December 2019 https://doi.org/10.1038/s41893-019-0461-5

\footnotetext{
References

1. Twenty Questions About Design Behaviour for Sustainability (International Expert Panel on Behavioural Science for Design, New York, 2019); https://www.nature.com/natsustain/ expertpanels
} 